\title{
Tensile properties and microstructure of rheo-diecast 7075 alloy prepared by serpentine channel process
}

\author{
*Wei-min Mao' and Wen-zhi Zhu',2 \\ 1. School of Materials Science and Engineering, University of Science \& Technology Beijing, Beijing 100083, China \\ 2. State Key Laboratory of Materials Processing and Die \& Mould Technology, Huazhong University of Science \& Technology, Wuhan 430074, \\ China
}

\begin{abstract}
A semisolid slurry of 7075 aluminum alloy was prepared by means of a serpentine channel process (SCP) and rheo-diecasting. The influences of pouring temperature during slurry preparation, the injection pressure and die preheat temperature on the mechanical properties and microstructure of a rheo-diecast 7075 aluminum alloy were investigated. The results show that the as-cast strength and elongation of the tensile samples were 210-260 MPa and $0.2 \%-1.7 \%$, respectively, with an injection pressure of $130 \mathrm{MPa}$, a pouring temperature of $700-720^{\circ} \mathrm{C}$, a preheat temperature of $280-350^{\circ} \mathrm{C}$, and a plunger speed of $0.5 \mathrm{~m} \cdot \mathrm{s}^{-1}$. The results also show that the aged strength and elongation of the tensile samples were $420-453 \mathrm{MPa}$ and $1.0 \%-1.4 \%$, respectively, when the alloy solution was treated at $470{ }^{\circ} \mathrm{C}$ for $12 \mathrm{~h}$ and aged at $120^{\circ} \mathrm{C}$ for $24 \mathrm{~h}$. The substantial shrinkage porosity in the 7075 aluminum alloy tensile samples was the main cause of low elongation.
\end{abstract}

Key words: serpentine channel; rheo-die casting; 7075 aluminum alloy; microstructure; tensile properties.

CLC numbers: TG146.21 Document code: A

Article ID: 1672-6421(2019)03-161-07

\begin{abstract}
Cemisolid metal (SSM) processing was put forward by Flemings et al. ${ }^{[1]}$ in the 1970 s and has drawn increasing attention among researchers and industrial enterprises over the past four decades. The most important characteristic of semisolid casting technology is that the morphological structure of the primary solid phase in the microstructure is spherical. To meet this demand, a wide spectrum of routes and processes have been developed to prepare semisolid alloy slurries. Conventional preparation processes generally apply mechanical or electromagnetic stirring methods ${ }^{[2-7]}$. However, conventional preparation processes require specialized equipment so that they are complex and consume a substantial amount of energy, and the metal semisolid slurry or billet is more expensive. Recently, a controlled nucleation method was reported, which is straight forward, practical, and less expensive because of the lack of mechanical or electromagnetic stirring. According to this method, several preparation processes were developed, such as the New Rheocasting process ${ }^{[8,9]}$, vertical pipe process ${ }^{[10]}$, rotating duct process ${ }^{[11,12]}$, Damper Cooling
\end{abstract}

\section{*Wei-min Mao}

Male, born in 1958, Ph.D, Professor. His research interests mainly focus on semi-solid processing of metallic materials. To date, he has published over 250 technical papers and two monographs.

E-mail: mao_wm@ustb.edu.cn

Received: 2018-12-25; Accepted: 2019-03-12
Tube process ${ }^{[13]}$, wavelike sloping plate process ${ }^{[14,15]}$, subliquidus casting process ${ }^{[16]}$, cup-cast process ${ }^{[17]}$, and self-inoculation process ${ }^{[18]}$. There is a similarity among these processes; that is to say, an alloy melt is poured through a plate or pipe without mechanical or electromagnetic stirring. Therefore, these preparation processes are straight forward and the slurry cost and energy consumption are low.

The serpentine channel process was proposed several years ago and is a new preparation method for semisolid alloy slurries ${ }^{[19]}$. When a sufficiently superheated liquid aluminum alloy is poured into a graphite or copper serpentine channel, the primary grains in the slurry flow out of the channel and are refined and form a spherical or degenerated dendritic structure ${ }^{[20-23]}$. Moreover, this method has several advantages, such as simplicity, straight forward preparation, ease of operation, and low production cost. Due to the traditional solidification features of a 7075 aluminum alloy, it is difficult to cast a complicated thin-walled casting with liquid 7075 aluminum alloy by a traditional casting method. A semisolid 7075 aluminum alloy slurry was rheo-diecast to take advantage of the semisolid casting benefits and explore the possibility of rheo-diecasting with a semisolid 7075 aluminum alloy slurry prepared by means of a serpentine channel process. The tensile properties and microstructure of the rheo-diecast tensile samples were investigated. 


\section{Experimental procedure}

A commercial 7075 aluminum alloy was used for the experiments, and its chemical compositions are listed in Table 1. The liquidus and solidus temperatures of the alloy are $640{ }^{\circ} \mathrm{C}$ and $477{ }^{\circ} \mathrm{C}$, respectively, as determined by differential scanning calorimetry (DSC).

Table 1: Chemical compositions of commercial 7075 aluminum alloy (wt.\%)

$\begin{array}{ccccccc}\mathrm{Cu} & \mathrm{Mg} & \mathrm{Zn} & \mathrm{Fe} & \mathrm{Cr} & \mathrm{Si} & \mathrm{Al} \\ 1.7 & 2.2 & 5.9 & 0.50 & 0.23 & 0.40 & \text { Balanced }\end{array}$

A graphite serpentine channel with 5 curves and a 25 $\mathrm{mm}$ inner diameter was used to prepare the semisolid 7075 aluminum alloy slurry, and the channel was at room temperature before the liquid 7075 aluminum alloy was poured. A nonmetallic REM ladle preheated to $400-500{ }^{\circ} \mathrm{C}$ was used to collect the slurry, and the slurry was then carried into the chamber of the YYC180B die-casting machine and rheo-diecast at once, as shown in Fig. 1. The plunger speed was $0.5 \mathrm{~m} \cdot \mathrm{s}^{-1}$, and the pressure holding time was 5-6 s during rheo-diecasting. The hold duration of the casting in the die was $5-6 \mathrm{~s}$ after opening the die. The chamber was preheated to $300-400{ }^{\circ} \mathrm{C}$ before rheodiecasting. A TESNR-81535A surface thermocouple was used to measure the temperatures of the chamber and the die wall, and the temperature displayed was accurate to $\pm 1{ }^{\circ} \mathrm{C}$.

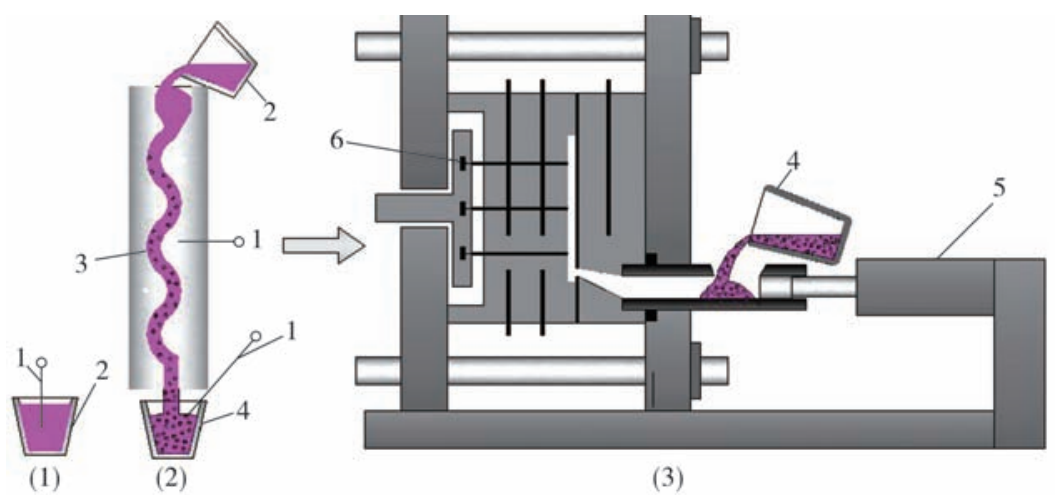

(1) Melting and temperature control (2) Slurry preparation (3) Rheo-die casting 1- K-type thermocouple; 2-melting crucible; 3-serpentine channel; 4-laddle; 5-die casting machine; 6-heating rod

Fig. 1: Schematic of rheo-die casting process by means of serpentine channel process

To investigate the effect of process parameters (pouring temperature for slurry preparation, injection pressure and preheat temperature of the die) on the tensile properties and microstructure of the alloy, the following values, as shown in Table 2, were used during the rheo-diecast experiments.

Table 2: Technological parameters during rheo-die cast experiments for semi-solid 7075 aluminum alloy

\begin{tabular}{ccc|}
$\begin{array}{c}\text { Pouring } \\
\text { temperature } \\
\left({ }^{\circ} \mathbf{C}\right)\end{array}$ & $\begin{array}{c}\text { Injection } \\
\text { pressure } \\
(\mathrm{MPa})\end{array}$ & $\begin{array}{c}\text { Preheated temperature } \\
\text { of die mould }\left({ }^{\circ} \mathrm{C}\right)\end{array}$ \\
760 & & \\
740 & 130 & \\
720 & 90 & $280-350$ \\
700 & 60 & $180-280$ \\
680 & 30 & \\
660 & & \\
\end{tabular}

The rheo-diecasting is shown in Fig. 2. The two tensile samples in the middle were $5 \mathrm{~mm}$ thick, and the two tensile samples on the side were $3 \mathrm{~mm}$ thick. The tensile samples were machined to a standard size by wire-electrode cutting, as shown in Fig. 3. The heat treatment process for tensile samples was as follows. They were solution treated at $470{ }^{\circ} \mathrm{C}$ for $12 \mathrm{~h}$ and then

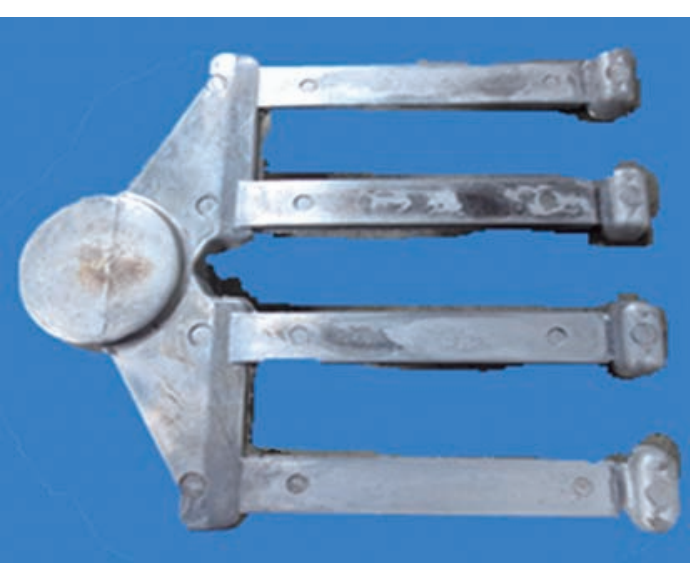

Fig. 2: Tensile samples of rheo-diecasting

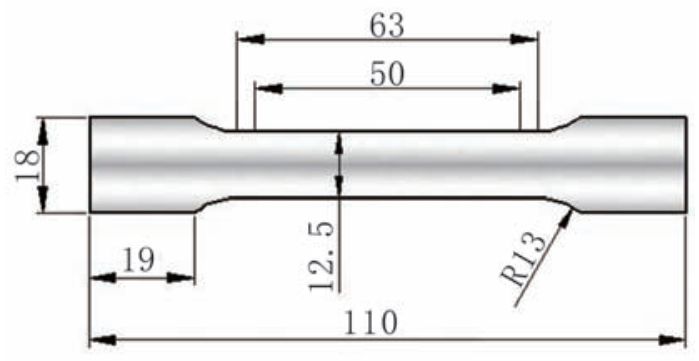

Fig. 3: Standard sizes of a tensile sample ( $\mathrm{mm})$ 
aged at $120^{\circ} \mathrm{C}$ for $8,16,24$ and $36 \mathrm{~h}$. The tensile strength and elongation of the tensile samples were tested on a CMT 4105 tensile test machine with a speed of $2 \mathrm{~mm} \cdot \mathrm{min}^{-1}$. A total of 3 to 6 samples were tested for every set of process parameters.

The metallographic specimens were cut from the samples after tensile testing. The mean particle diameter (MPD) and average shape factor (ASF) of the primary $\alpha$-Al grains were determined.

\section{Results and discussion}

\subsection{Effect of pouring temperature on the tensile properties and microstructure of rheo-diecast 7075 alloy}

To study the effect of pouring temperature during slurry preparation on the subsequent rheo-diecasting process, pouring temperatures of $760,740,720,700,680$ and $660{ }^{\circ} \mathrm{C}$ were used, while the injection pressure was $130 \mathrm{MPa}$, and the preheat temperature of the die was $280-350{ }^{\circ} \mathrm{C}$. The as-cast tensile properties of the corresponding tensile samples are shown in Table 3 , which shows that the pouring temperatures had no obvious effect on the as-cast tensile strengths, and all the elongations were very low. Therefore, the proper pouring temperature range is $680-$

Table 3: As-cast tensile properties of rheo-die cast $7075 \mathrm{Al}$ alloy under different pouring temperatures

\begin{tabular}{ccc|}
$\begin{array}{c}\text { Pouring temperature } \\
\left({ }^{\circ} \mathbf{C}\right)\end{array}$ & $\begin{array}{c}\text { Tensile strength } \\
(\mathrm{MPa})\end{array}$ & Elongation (\%) \\
\hline 760 & $225-229$ & $0.5-1.6$ \\
740 & $210-221$ & $0.7-1.5$ \\
720 & $212-226$ & $0.4-1.7$ \\
700 & $210-225$ & $0.2-1.6$ \\
680 & $211-224$ & $0.5-1.3$ \\
660 & $185-210$ & $0.8-1.4$ \\
\hline
\end{tabular}

$760{ }^{\circ} \mathrm{C}$ when considering the tensile strength.

The as-cast microstructure of the rheo-diecast 7075 aluminum alloy, ASF and MPD of the primary $\alpha$-Al grains at different pouring temperatures are shown in Fig. 4 and Table 4 . When the slurry was prepared at $760{ }^{\circ} \mathrm{C}$, the majority of the primary $\alpha-\mathrm{Al}$ grains in the center of the sample were rosette-like and large in size, and the spherical primary $\alpha-\mathrm{Al}$ grains were few in number, as shown in Fig. 4(a). As the pouring temperature decreased to $740{ }^{\circ} \mathrm{C}$, the majority of the primary $\alpha$-Al grains in the center of the sample were spherical, but the grain size was also large, as shown in Fig. 4(c). As the pouring temperature further decreased to $720{ }^{\circ} \mathrm{C}$ and $700{ }^{\circ} \mathrm{C}$, the majority of the primary $\alpha$-Al grains were spherical and refined, as shown in Fig. $4(\mathrm{e})$ and $(\mathrm{g})$. The morphology of the primary $\alpha$-Al grains in the center of the samples is similar to Fig. 4(e) and (g) if the slurry was prepared at $680{ }^{\circ} \mathrm{C}$ and $660{ }^{\circ} \mathrm{C}$, but the amount of slurry sticking on the channel increased and the channel was easily blocked, so the stability of slurry preparation was affected. It can be seen from the edge microstructure that there was liquid segregation on the sample surface, and this liquid segregation was more serious when the slurry was prepared at $760{ }^{\circ} \mathrm{C}$. There were a few primary $\alpha$ - $\mathrm{Al}$ grains in the liquid segregation layers, as shown in Fig. 4(b), (d), (f) and (h). The liquid segregation on the sample surface should be related to the flowability during rheo-diecasting. The flowability of the primary $\alpha$-Al grains and liquid in a 7075 aluminum alloy slurry is different, and the liquid moved around the primary $\alpha-\mathrm{Al}$ grains under the filling pressure. Therefore, the liquid flowed to areas with a low pressure or to the free surface of the tensile sample that was not restricted. In addition, the slurry of the 7075 aluminum alloy and the surface of the die were in close contact with each other during rheo-diecasting; thus, the sample surface solidified quickly, and the contraction speed was faster than that of the inner area. Therefore, the volumetric contraction produced capillary absorption of the liquid in the inner sample area, and
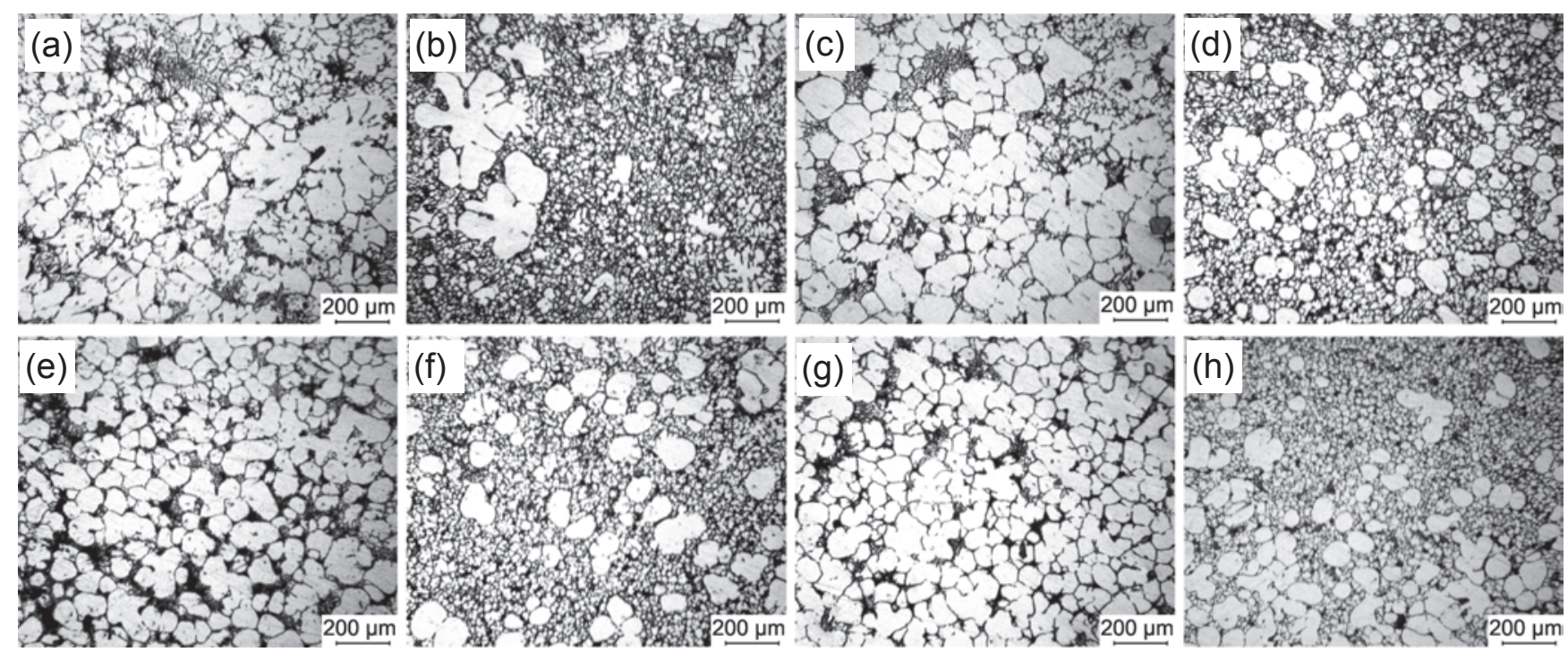

Fig. 4: Microstructures of rheo-die cast samples with different slurry preparation temperatures: (a) $760{ }^{\circ} \mathrm{C}$, center; (b) $760^{\circ} \mathrm{C}$, edge; (c) $740{ }^{\circ} \mathrm{C}$, center; (d) $740{ }^{\circ} \mathrm{C}$, edge; (e) $720^{\circ} \mathrm{C}$, center; (f) $720^{\circ} \mathrm{C}$, edge; (g) $700^{\circ} \mathrm{C}$, center; (h) $700^{\circ} \mathrm{C}$, edge 
Table 4: ASF and MPD of primary $\alpha-A l$ grains in rheo-die cast 7075 aluminum alloy

\begin{tabular}{|ccc|}
$\begin{array}{c}\text { Pouring temperature } \\
\left({ }^{\circ} \mathrm{C}\right)\end{array}$ & ASF & MPD $(\mu \mathrm{m})$ \\
760 & - & - \\
740 & 0.51 & 147 \\
720 & 0.69 & 83 \\
700 & 0.70 & 69 \\
\hline
\end{tabular}

the liquid was eventually absorbed on the sample surface that solidified and contracted previously.

As a result, the proper pouring temperature for the preparation of a 7075 aluminum alloy slurry is $700-720{ }^{\circ} \mathrm{C}$, considering the tensile strength and microstructure, because the corresponding as-cast tensile strengths were higher and the primary $\alpha$-Al grains were finer and more spherical than those at other pouring temperatures; in addition, the slurry sticking to the channel and the liquid segregation on the sample surface were less.

\subsection{Effect of injection pressure on tensile properties and microstructure of rheo- diecast 7075 alloy}

To study the effect of injection pressure on the tensile properties of the rheo-diecast 7075 alloy, different injection pressures of 130, 90, 60 and $30 \mathrm{MPa}$ were used. The pouring temperature for slurry preparation was $720^{\circ} \mathrm{C}$ based on the discussion above, and the preheat temperature of the die was $280-350{ }^{\circ} \mathrm{C}$.

The tensile properties of the rheo-diecast 7075 aluminum alloy are shown in Table 5. The tensile strengths gradually increased with increasing injection pressure, and the elongation also increased. Hence, the proper injection pressure is $130 \mathrm{MPa}$ because the corresponding as-cast elongation was higher than at other pressures, and the highest value is greater than $1.0 \%$.

Table 5: As-cast tensile properties rheo-die cast under different injection pressure

\begin{tabular}{ccc|}
$\begin{array}{c}\text { Injection pressure } \\
\text { (MPa) }\end{array}$ & $\begin{array}{c}\text { Tensile strength } \\
(\mathrm{MPa})\end{array}$ & $\begin{array}{c}\text { Elongation } \\
(\%)\end{array}$ \\
\hline 130 & $212-226$ & $0.4-1.7$ \\
90 & $201-210$ & $0.3-0.6$ \\
60 & $197-204$ & $0.2-0.4$ \\
30 & $160-176$ & - \\
\hline
\end{tabular}

Figure 5 shows the microstructures of the rheo-diecast samples. It can be seen from Fig. 5 (a) and (b) that the spherical primary $\alpha$-Al grains on the sample center were distributed uniformly when the injection pressure was $130 \mathrm{MPa}$, but there was also liquid segregation on the sample edge. When the injection pressure was $90 \mathrm{MPa}$, the microstructures of the samples are similar to Fig. 5(a) and (b), as shown in Fig. 5(c) and (d). When the injection pressures were 60 and $30 \mathrm{MPa}$, the morphology of the primary $\alpha$-Al grains on the sample center was poor, and there was also liquid segregation on the sample edge, as shown in Fig. 5(e) and (f). Therefore, the primary $\alpha$-Al grains were more spherical, and the distribution of the primary $\alpha$-Al grains was more homogeneous when the injection pressure was 90-130 MPa.
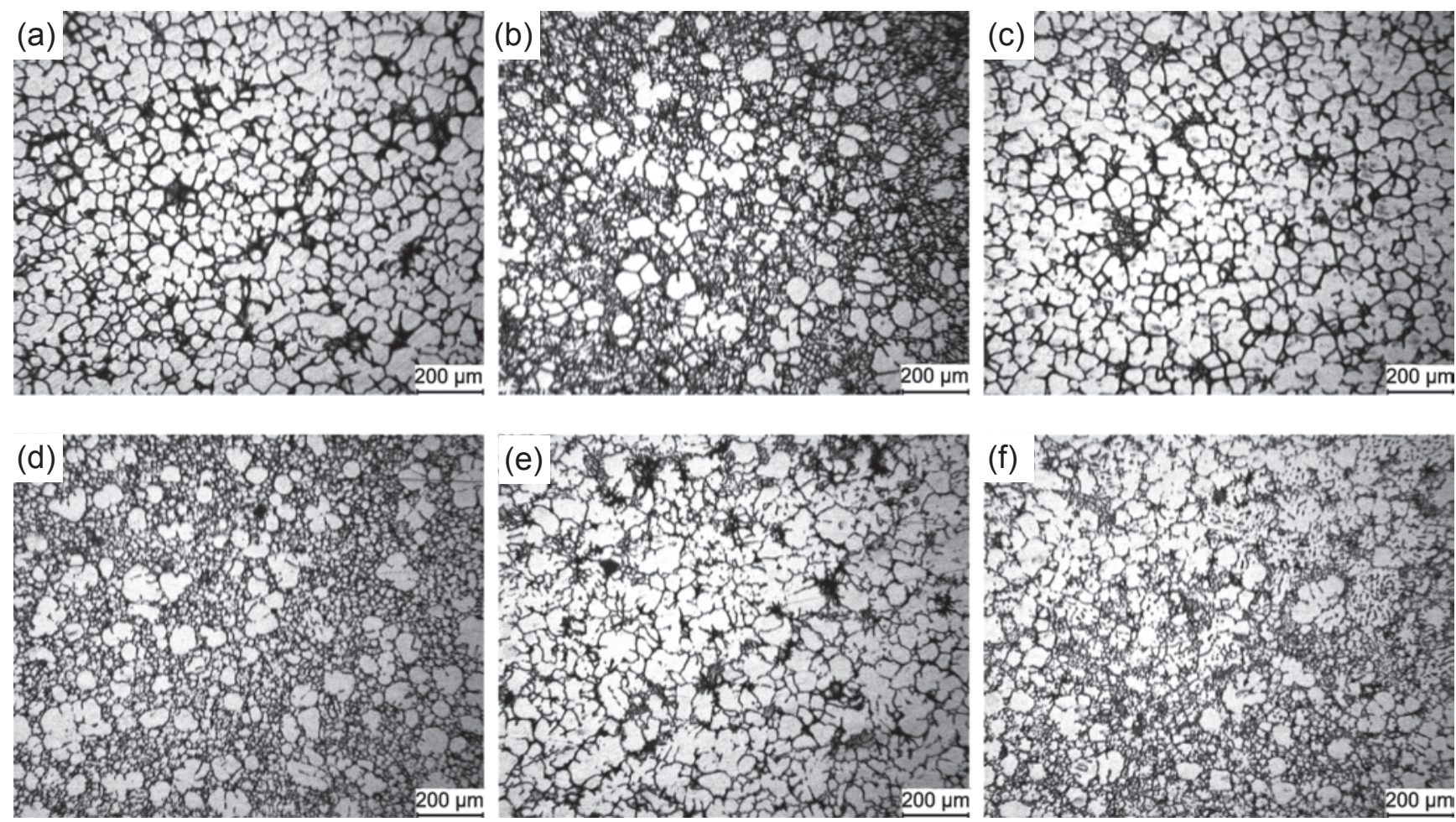

Fig. 5: Microstructures of rheo-die cast tensile samples with different injection pressures: (a) $130 \mathrm{MPa}$, center; (b) $130 \mathrm{MPa}$, edge; (c) $90 \mathrm{MPa}$, center; (d) $90 \mathrm{MPa}$, edge; (e) $60 \mathrm{MPa}$, center; (f) $60 \mathrm{MPa}$, edge 


\subsection{Effect of preheated die temperature on tensile properties and microstructure of rheo-diecast 7075 alloy}

To study the effect of the preheat temperature of the die on the rheo-diecast 7075 alloy, the given conditions are as follows. The injection pressure was $130 \mathrm{MPa}$, and the pouring temperature for the slurry was $720^{\circ} \mathrm{C}$.

The tensile properties of the rheo-diecast 7075 aluminum alloy are shown in Table 6. In accordance with the tensile tests of the rheo-diecast 7075 aluminum alloy, the as-cast tensile properties were slightly higher when the preheated die temperature was in the range of $280-350{ }^{\circ} \mathrm{C}$, the strengths were between $210 \mathrm{MPa}$ and $221 \mathrm{MPa}$, and the elongations were between $0.7 \%$ and $1.5 \%$. The as-cast tensile properties were slightly lower when the preheated die temperature was below $280{ }^{\circ} \mathrm{C}$, the strengths were between $201 \mathrm{MPa}$ and 218 $\mathrm{MPa}$, and the elongations were between $0.4 \%$ and $1.2 \%$.

Table 6: As-cast tensile properties rheo-die cast under different preheated temperature of die mould

$\begin{array}{ccc}\begin{array}{c}\text { Preheated temperature } \\ \text { of die mould }\left({ }^{\circ} \mathrm{C}\right)\end{array} & \begin{array}{c}\text { Tensile strength } \\ (\mathrm{MPa})\end{array} & \begin{array}{c}\text { Elongation } \\ (\%)\end{array} \\ \geqslant 280 & 210-221 & 0.7-1.5 \\ 180-280 & 201-218 & 0.4-1.2\end{array}$

If the preheat temperature of the die mold is higher during rheo-diecasting, the chilling effect of the die wall on 7075 aluminum alloy slurry is weaker, and the flowing ability of the slurry is better. Thus, the tensile samples can be denser and filled more completely so that the tensile properties can be improved. If the preheat temperature of the die mold is lower, the chilling effect of the die wall on 7075 aluminum alloy slurry is stronger, and the flowability of the slurry decreases. Then, the tensile samples may not be as dense and completely filled, so that the tensile properties are worse. Moreover, the solidification sensitivity to the temperature of the 7075 aluminum alloy is very high, and the local slurry that is chilled by the die wall can solidify very quickly; the low-melting-point liquid is then unable to fill the area with contracted solid material, so the tensile samples easily form shrinkage porosity or hot tearing, and the tensile properties become worse. It was found that when the preheat temperature of the die mold was below $100{ }^{\circ} \mathrm{C}$, the probability for the tensile samples to form shrinkage porosity or hot tearing increased substantially.

After metallographic examination, it was found that the preheat temperature of the die mold had almost no effect on the microstructures of the tensile samples, and there was also the same liquid segregation on the sample surface. However, when the preheat temperature of the die mold was above 280 ${ }^{\circ} \mathrm{C}$, the filling ability of the 7075 aluminum alloy slurry was better, the tensile samples and the overflow grooves were filled thoroughly, and the surface of the samples was light and dense. When the preheat temperature of the die mold was below $280{ }^{\circ} \mathrm{C}$, the filling ability of the slurry decreased, the tensile samples and the overflow grooves were not filled thoroughly, the surface of the samples was gray and the density was lower. Therefore, the preheat temperature of the die mold for 7075 aluminum alloy rheo-diecasting should be higher than $280^{\circ} \mathrm{C}$.

\subsection{Effect of aging time on the tensile properties and microstructure of rheo- diecast $\mathbf{7 0 7 5}$ alloy}

To compare the effect of aging time on the tensile properties of the rheo-diecast 7075 aluminum alloy, the conditions are as follows. The solution temperature was $470{ }^{\circ} \mathrm{C}$, solution time was $12 \mathrm{~h}$, aging temperature was $120^{\circ} \mathrm{C}$, pouring temperature for slurry making was $720^{\circ} \mathrm{C}$, injection pressure was $130 \mathrm{MPa}$ and reheated temperature of the die mold was $280-350^{\circ} \mathrm{C}$.

When the aging temperature was $120^{\circ} \mathrm{C}$, the tensile strength of the rheo-diecast samples first increased gradually with increasing aging time and then decreased after reaching the peak value, but the elongation had almost no variation and was very low, as shown in Table 7 . When the aging time was $24 \mathrm{~h}$, the strength reached the highest value of $453 \mathrm{MPa}$, and the elongation was also low with a maximum value of $1.4 \%$.

Table 7: Effect of aging time on tensile properties of 7075 aluminum alloy rheo-die cast

\begin{tabular}{ccc|}
$\begin{array}{c}\text { Aging time } \\
\text { (h) }\end{array}$ & $\begin{array}{c}\text { Tensile strength } \\
\text { (MPa) }\end{array}$ & $\begin{array}{c}\text { Elongation } \\
(\%)\end{array}$ \\
\hline 8 & $330-340$ & $0.8-1.1$ \\
16 & $338-357$ & $0.7-1.2$ \\
24 & $420-453$ & $1.0-1.4$ \\
32 & $395-410$ & $0.9-1.3$ \\
\hline
\end{tabular}

\subsection{Fracture analysis of tested tensile samples}

Considering the tensile properties in Section 2.1 through Section 2.3, the as-cast tensile elongations of the rheo-diecast 7075 aluminum alloy under the given conditions are very low. Therefore, it was necessary to analyze the fracture morphology of tensile samples. The center area of the fractured tensile samples appeared to have a low density and substantial shrinkage porosity under the given processing parameters, as shown in Fig. 6. It was concluded from Fig. 6 that the tensile fracture may be caused by the center shrinkage porosity to a large extent, and this may be the main cause of the very low elongation.

It was helpful to observe the shrinkage porosity in the center area of the fracture at higher magnification, as shown in Fig. 7. There is a large number of smooth primary $\alpha$-Al grains in the center area of the fracture, which means that the shrinkage porosity formed between the primary $\alpha-\mathrm{Al}$ grains because the low-melting-point liquid could not backfill that area. Therefore, substantial porosity was present in the ascast tensile samples. The binding force between the smooth primary $\alpha-\mathrm{Al}$ grains decreased. Microcracks were produced in the weak areas between the smooth primary $\alpha$-Al grains during the tensile test, and the microcracks gradually extended until fractures occurred along the smooth primary $\alpha-\mathrm{Al}$ grains. It is 

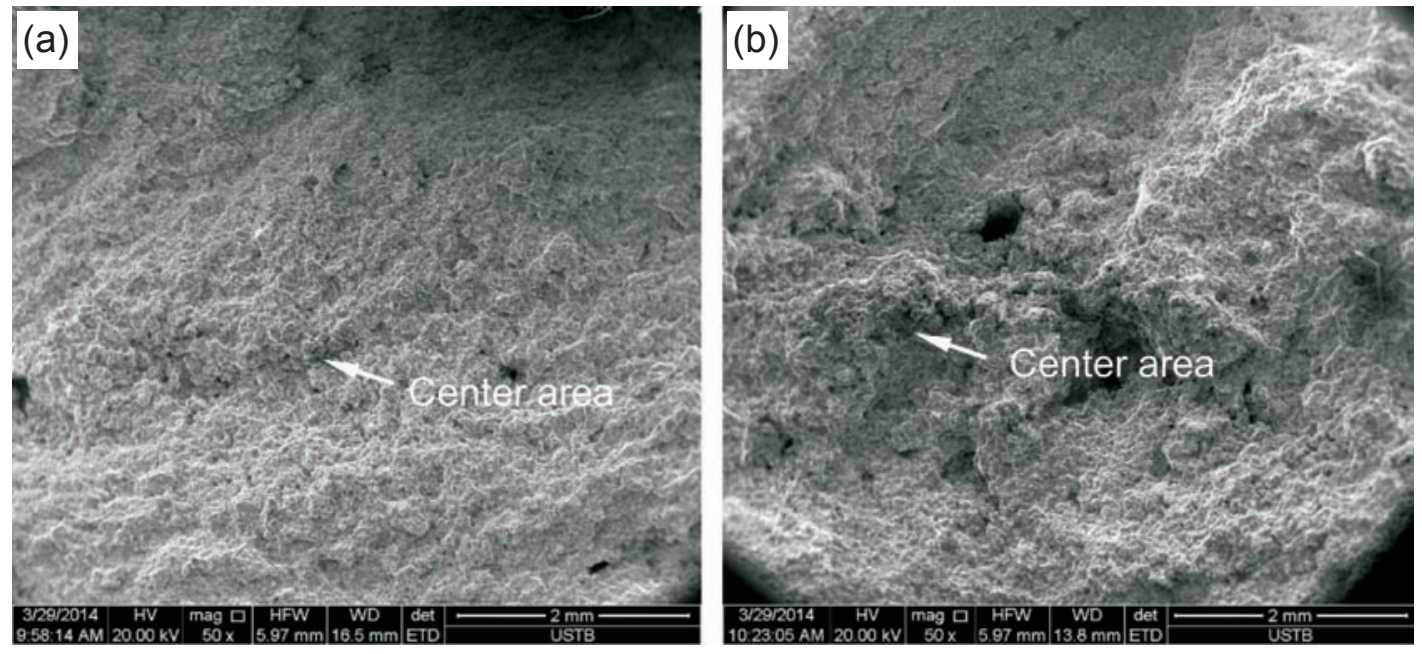

Fig. 6: Fracture morphology of as-cast tensile samples at low magnification: (a) $760^{\circ} \mathrm{C}$, $130 \mathrm{MPa}, 280-350^{\circ} \mathrm{C}$; (b) $720^{\circ} \mathrm{C}, 60 \mathrm{MPa}, 280-350^{\circ} \mathrm{C}$
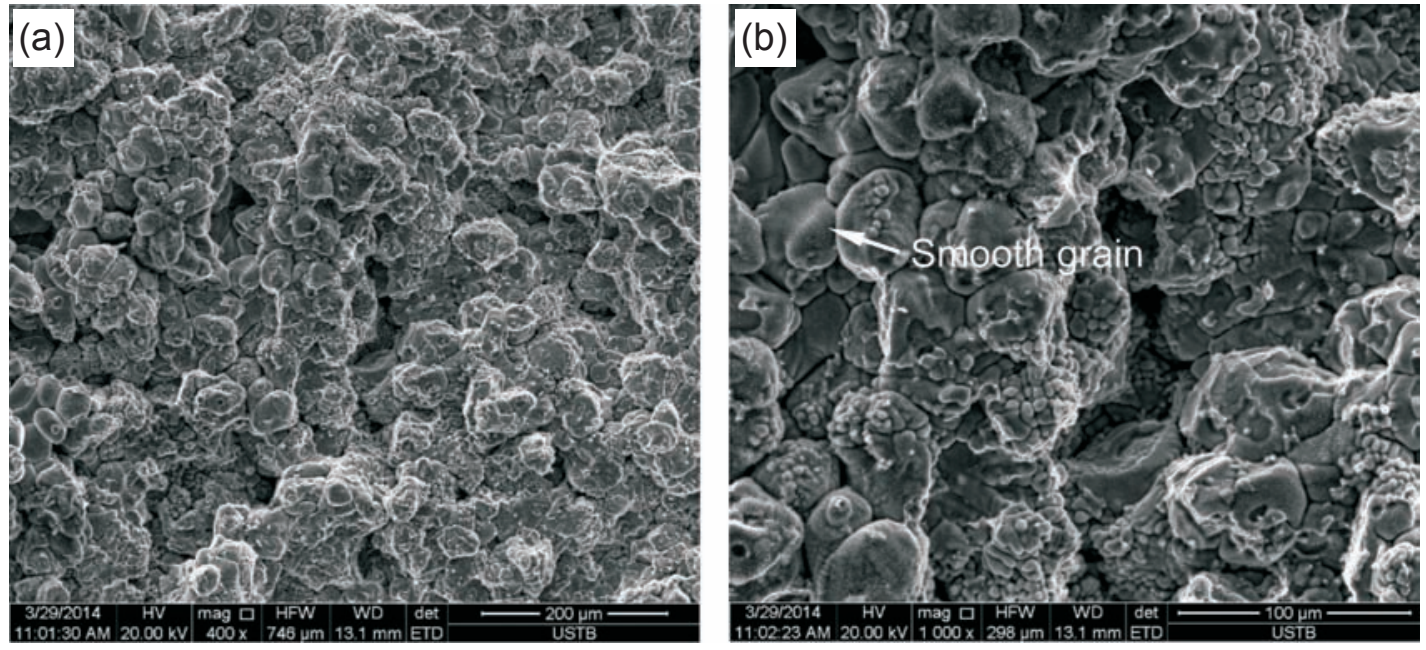

Fig.7: Fracture morphology along primary $\alpha-A \mathrm{l}$ grains of as-cast tensile samples: (a) $660^{\circ} \mathrm{C}$, $130 \mathrm{MPa}, 280-350^{\circ} \mathrm{C}$; (b) $660^{\circ} \mathrm{C}, 130 \mathrm{MPa}, 280-350^{\circ} \mathrm{C}$

evident that the fracture along the smooth primary $\alpha$-Al grains was the main cause for the very low elongation of the as-cast rheo-diecast 7075 aluminum alloy.

Figure 7 also indicates that a high pressure of $130 \mathrm{MPa}$ did not help to transport material to the final solidification areas in the sample center because of the thin wall or filling distance. Therefore, the last low-melting-point liquid or slurry in the sample center solidified under no pressure or lower pressure, the solidification shrinkage did not obtain enough liquid to compensate for the shrinkage, and substantial shrinkage porosity occurred. The solidification phenomenon of the ascast tensile samples described above was reflected in the very low elongation.

After an effective solution and aging treatment, the majority of secondary phase $\mathrm{MgZn}_{2}$ dissolved, and strong precipitation strengthening was generated. Therefore, the tensile strength of the aged samples greatly increased. Many river-like tearing ridges and dimples were found in the fracture. However, the shrinkage porosity cannot be eliminated after solution and aging treatment, as shown in Fig. 8. Therefore, the elongation after aging treatment was also low, and this indirectly restricted a further increase of the tensile strength.

\section{Conclusions}

(1) The as-cast strength and elongation of the rheo-diecast 7075 aluminum alloy are $210-260 \mathrm{MPa}$ and $0.2 \%-1.7 \%$, respectively, at an injection pressure of $130 \mathrm{MPa}$, pouring temperature of $700{ }^{\circ} \mathrm{C}-720^{\circ} \mathrm{C}$, preheat temperature of $280{ }^{\circ} \mathrm{C}-$ $350{ }^{\circ} \mathrm{C}$ and plunger speed of $0.5 \mathrm{~m} \cdot \mathrm{s}^{-1}$.

(2) The aged strength and elongation of the 7075 rheodiecast aluminum alloys are 420-453 $\mathrm{MPa}$ and $1.0 \%-1.4 \%$, respectively, at a solution temperature of $470{ }^{\circ} \mathrm{C}$, a solution time of $12 \mathrm{~h}$, an aging temperature of $120^{\circ} \mathrm{C}$ and an aging time of $24 \mathrm{~h}$.

(3) The serious shrinkage porosity in the rheo-diecast 7075 aluminum alloy tensile samples is the main cause of the very low resultant elongation. 

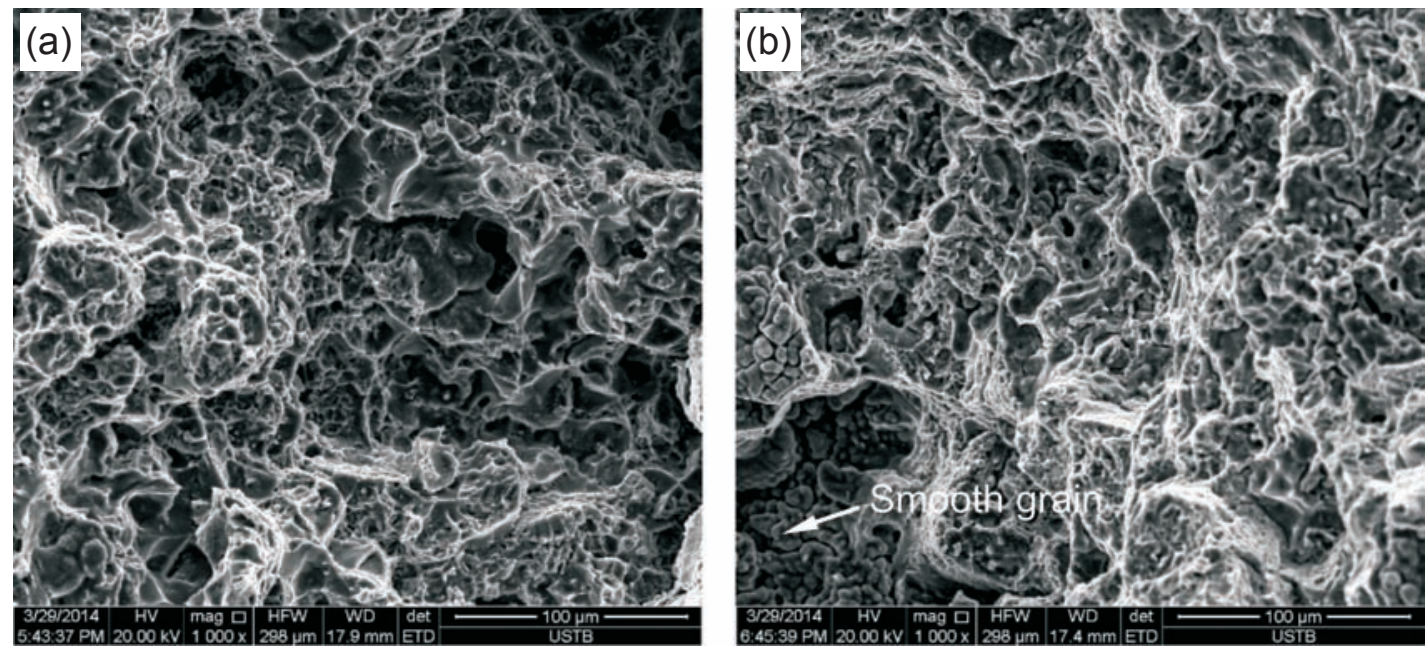

Fig. 8: Fracture morphology of tensile samples aged for different times: (a) 24 h; (b) 36 h

\section{References}

[1] Flemings M C. Behavior of metal alloys in the semi-solid state. Metallurgical and Materials Transaction A, 1991, 22(5): 957981.

[2] Brook, G B. Improving the quality of aluminum diecastings by novel techniques. Materials \& Design, 1982, 3(5): 558-565.

[3] Yang H, Tian W T. Metallurgical structure of A356 alloy solidified by mechanical stirring. Solid State Phenomena, 1998, 285: 183-188.

[4] Midson S P. The commercial status of semi-solid casting in the USA. In: Proc. of the 4th Inter. Conf. on Semi-Solid Processing of Alloys and Composites, edited by Kirkwood D H and Kapranos P, University of Sheffield, England, June 19-21, 1996: 251-255.

[5] Sahm P R. SSM in Europe. In: Proc. of the 5th Inter. Conf. on Semi-Solid Processing of Alloys and Composites, edited by Bhasin A K, Moore J J, Young K P and Midson S, Golden, Colorado, June 23-25, 1998.

[6] Guan TY, Zhang Z F, He M, et al. Effects of annular electromagnetic stirring melt treatment on microstructure and mechanical properties of 7050 rheo-casting. Solid State Phenomena, 1998, 285: 219223.

[7] Flemings M C. Dendrite fragmentation in semisolid casting: could we do this better? Solid State Phenomena, 2018, 285: 3-11.

[8] Lukasson M, Apelian D, Dasgupta R. Alloy characterization for the new UBE rheocasting process. AFS Trans., 2002, 110: 271-284

[9] Legoretta E C, Atkinson H V, Jones H. Cooling slope casting to obtain thixotropic feedstock. II: Observations with A356 alloy. Journal of Materials Science, 2008, 43(16): 5456-5469.

[10] Yang X R, MAO W M, PEI S. Preparation of semi-solid A356 alloy feedstock cast through vertical pipe. Materials Science and Technology, 2007, 23(9): 1049-1053.

[11] Guo H M, Yang X J, Hu B. Rheocasting of aluminum alloy A356 by low superheat pouring with a shear field. Acta Metallurgica Sinica, 2006, 19(5): 328-334.

[12] Yang X J, Guo H M. Microstructure evolution and mechanical properties of rheoformed YL112 aluminum alloy. Solid State Phenomena, 2008, 141-143:163-168.
[13] Zhang Xiao-li, XieShui-sheng, Li Yan-ju, et al. A356 aluminum alloy semisolid slurry prepared by damper cooling tube process. Rare Metal Material and Engineering, 2007, 36(5): 915-919.

[14] GuanRen-guo, LiJian-ping, Chen Li-qing, et al. Mechanism alloy microstructure formation during vibrating wavelike sloping plate process. Transactions of Material Research, 2008, 22(4): 363-368.

[15] Guan R G, Cao F R, Chen L Q, et al. Dynamical solidification behaviors and microstructural evolution during vibrating wavelike sloping plate process. Journal of Materials Processing Technology, 2009, 209: 2592-2601.

[16] Forn A, Menargues S, Martin E, et al. Sub liquidus casting technology for the production of high integrity component. Solid State Phenomena, 2008, 141-143: 219-224.

[17] Pahlevani F, Azai K, Niyama E. Quick semi-solid slurry making method using metallic cup. Solid State Phenomena, 2008, 141-143: 463-468.

[18] Li Y D, Yang J, Ma Y, et al. Effect of pouring temperature on the microstructure of the semi-solid slurry of AM60 magnesium alloy by self-inoculation method (I). The Chinese Journal of Nonferrous Metals, 2010, 20(6): 1046-1052. (In Chinese)

[19] Mao W M, Yang X R, Tang G X, et al. A method of preparation of semi-solid alloys slurry and rheo-forming. China Patent ZL200710062977.6, Jan. 26th, 2007.

[20] Mao W M, Chen Z Z, Liu H W, et al. Preparation and rheodie casting of semi-solid A356 aluminum alloy slurry through a serpentine pouring channel. Solid State Phenomina, 2012, 192-193: 404-409.

[21] Zhu Wen-zhi, Mao Wei-min, Tu Qin. Preparation of semi-solid 7075 aluminum alloy slurry by serpentine pouring channel. Transactions of Nonferrous Metals Society of China, 2014, 24(4): 954-960.

[22] Zheng Z K, Mao W M, Liu Z Y, et al. Refinement of primary Si grains in $\mathrm{Al}-20 \% \mathrm{Si}$ alloy slurry through serpentine channel pouring process. International Journal of Minerals, Metallurgy and Materials, 2016, 23(5): 572-580.

[23] Mao W M, Yan P Y, Zheng Z K. Preparation of semi-solid A390 aluminum alloy slurry through a serpentine pouring channel. Solid State Phenomena, 2018, 285: 169-175. 